\title{
Thermal Stress and Deformation of Steel Structures of High Rise Buildings in Fire
}

\author{
H. SAITO, H. UESUGI, and M. YAMAGUCHI \\ Department of Architectural Engineering \\ Faculty of Engineering, Chiba University \\ 1-33, Yayoicho Chiba 260, Japan
}

\author{
A. KODAIRA \\ Technical Research Laboratory \\ Takenaka Komuten Co., Ltd. \\ Minamisuna Koto-ku, Tokyo 136, Japan
}

ABSTRACT

In anelyzing themal stresses and deformation of a high rise steel structure, exposed to a compartment fire, it is convenient to divide the structure into (a) the local substmucture, directly fire exposed, (b) the adjacent substructure, comprising the nearest floors and spans around the fire compartment, and (c) the remaining part of the structure.

For substructure (a), the deformation behavior is normally elasto-plastic, for substructure (b) purely elastic. For the remaining part (c), the fire induced stresses and deformations are generally negligible.

This paper presents a method for the calculation of the stress and deformation behaviour of a high rise steel structure, exposed to a compartment fire, based on a subdivision of the structure as above. In order to illustrate the structural fire behaviour, 48 buildings have been analysed according to the method presented.

Keywords thermal stress, themal deformation, steel structure,plastic hinge, structural stability, yield temperature, structural divide

\section{INTRODUCTION}

Fire engineering design of building structures and structural members is generally, in Japan, carried out based on the results of standard fire resistance tests. The object of this design is to ensure the safety of structural members which are simply supported and bearing the maximum allowable service loads. Therefore, fire engineering design according to current laws and specifications gives a lower fire resistance than that of main structural members which are designed against seismic loads. Rational fire design of building structures can be made by analyzing the thermal stresses and deflections of building structures on the basis of temperature distribution of structural members and fire behavior in fire compartment,

Deflection behavior of a structural frame, exposed to fire, depends upon loading, reduction of load bearing capacity and stiffness and thermal stresses due to elevated temperature. Reductions of load bearing capacity have been thoroughly studied experimentally and experimental formulations have been suggested for elastic modulus, yield point and buckling stress of steel at elevated temperature/1-5/. The development of thermal stresses in steel structural members, generally, depends on end restraint conditions 
against thermal expansion and mechanical characteristics of steel at elevated temperature.

Prediction methods of steel structure and structural members have been developed rather earlier in elastic range /7,10,15/ and later also in elasto-plastic range $/ 6,8,9,11,17-23 /$. These methods, however, are primarily intended to be applied to multi-story frames because of limitation on computer capacity and are not well adapted to high rise building structures. The distribution and development of thermal stresses in high rise steel structure, exposed to the compartment fire, is localized around this compartment. Therefore, in analyzing thermal stresses and deformation of a high rise steel structure, exposed to a compartment fire, it is convenient to divide the structure into (a) the locel substructure, directly fire exposed, (b) the adjacent substructure, comprising the nearest floors and spans around the fire compartment, and (c) the remaining part of the structure. For substructure (a), the deformation behavior is normally elasto-plastic, for substructure (b) purely elastic. For the remaining part (c), the fire induced stresses and deformations are generally negligible/10,14/.

In this paper, we suggest a method of calculation of the restrained forces acting upon the local substructure and related deflections of the adjacent substructure. The determination of the restraint forces accurately takes into account the stiffness of and the forces within the total structure. The deflection of the adjacent substructure can rapidly be further transferred from one of the local substructure.

Using this calculation method, fire response is examined for 48 buildings, exposed to compartment fires.

\section{CALCULATION METHOD}

For the analysis of the state of thermal stresses and deflection at a compartment fire exposure, the steel structure is divided into the local substructure, the adjacent substructure and the surrounding substructure according to Fig.1. Thermal stresses and deflections are of importance for the local and adjacent substructures and practically negligible for the surrounding substructure. The analysis includes the influence of material and geometrical non-linearities. The local substructure is significantly affected by the fire exposure and must be analyzed in elasto-plastic range. The adjacent substructure is not affected directly by the fire exposure and behaves normally in elastic range. The equilibrium equation for the local substructure and the compatibility equation between integrated and incremental deformations are formulated as follows.

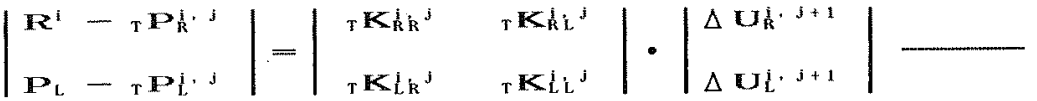

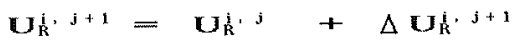

where capital letter $\mathbf{R}, \mathbf{P}, \mathbf{K}, \mathbf{U}$ mean end restraint force, external joint force, stiffness of substructure, displacement of joint, respectively. The subscript letter $R$, L mean that the quantity is related to the joint acted upon by the restraint force and the joint defined by segmentation of member in local substructure, respectively, and the subscript letter $T$ to the influence of temperature. The subscript $i$ and $j$ mean time step and i.terative step for approach to nonlinear phenomenon using linear relationship, respectively. $\mathbf{r P}_{\mathrm{R}}^{i}, \mathrm{rP}_{\mathrm{L}}^{\mathrm{i}} \mathbf{j}$ is joint force which is calculated by integration of interior stress, This stress is determined from stress-strain curve and history and instantaneous stress-related 

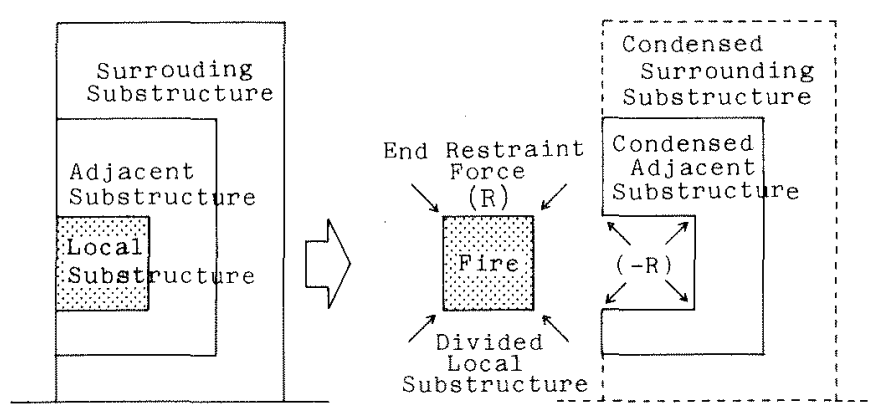

Fig. 1 Division of structure

strain is derived with subtracting thermal and creep strains from total strain. Therefore, the influence of instantaneous stress strain curve, thermal strain and creep strain dependent on time and temperature is fully included in the joint force $T \mathbf{P}_{\mathrm{R}}^{j}, \mathrm{~T} \mathbf{P}_{\mathrm{L}}^{\mathrm{i}} \mathrm{j}$.

The force equilibrium equation at joints in the adjacent and surrounding substructure is assembled, considering the end restraint force $\mathbf{R}$ reversely, acting upon the boundary joints between the local and adjacent substructure, as follows.

$$
\left|\begin{array}{l}
P_{R}-R^{i} \\
P_{A}
\end{array}\right|=\left|\begin{array}{ccc}
K_{R} & K_{R A} & 0 \\
K_{A R} & K_{A A} & K_{A G} \\
0 & K_{G A} & K_{G G}
\end{array}\right| \cdot\left|\begin{array}{l}
U_{R}^{i} \cdot j^{j+1} \\
U_{A} \\
U_{G}
\end{array}\right|+\left|\begin{array}{c}
0 P_{R} \\
0 P_{A} \\
0 P_{G}
\end{array}\right|-(3)
$$

where op is equivalent joint force due to intermediate loads acting on members in the adjacent and surrounding substructure. The subscript letter $A, G$ mean quantities related to the adjacent and surrounding substructure, respectively. The stiffness matrix $\mathbf{K}_{G a}, \mathbf{K}_{a A}$ and joint force vector o $P_{a}$, $P_{a}$ of the surrounding substructure are condensed and related only to the boundary joints between the local and adjacent substructure, The practical procedure of condensation is, firstly, upper back step elimination of $\mathbf{K}_{\mathrm{G} G}$ and secondary, unitization of $\mathbf{K}_{\mathrm{A} A}$ by square elimination and then the force equilibrium equation (3) are condensed in connection with the boundary displacement vector $\mathbf{U}_{R^{j}}^{j+1}$,

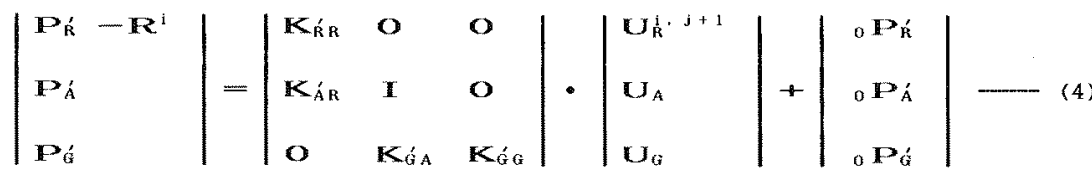

The end restraint force vector $\mathbf{R}^{i}$ is derived from the first line of the condensed equation (4), as follows.

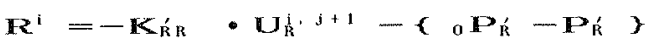

The end restraint force vector $\mathbf{R}^{\mathrm{j}}$ is formulated in terms of the 
condensed stiffness matrix $\mathbf{K}_{\mathbf{R}}$ ' solely related to the boundary joint

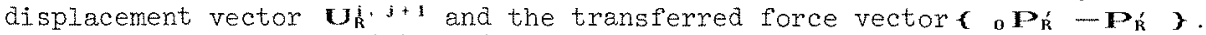
Substituting equation (5) in (1) and using the displacement compatibility equation (2), following equation is derived:

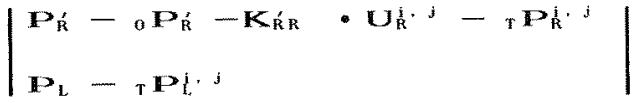

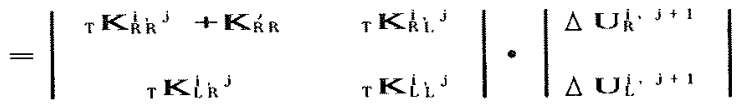

Calculation of incremental displacements $\Delta \mathbf{U}_{\mathbf{R}}^{\mathbf{i}} \mathbf{j + 1}, \Delta \mathbf{U}^{\mathbf{i},} \mathbf{j}^{\mathbf{j}+\mathbf{1}}$ is carried out iteratively according to Newton method and these values are converged to zero in the local. substructure at each time step.

The adjacent substructure joint displacement vector is derived from the second line of condensed equation (4) as follows.

$$
U_{A}=-K_{A K} \cdot U_{R}^{i} \cdot j+1+\left(P_{A}-{ }_{0} P_{A}^{\prime}\right)
$$

where the boundary displacement vector $\mathbf{U}_{\mathrm{R}}^{\mathbf{i}} \mathbf{j + l}$ is obtained from the analysis of the local substructure, considering the compatibility equation (2).

\section{NUMERICAL ANALYSIS}

The thermal stress analysis of high rise buildings is demonstrated. in the following, assuming a fire in some compartment. The local substructure which must be analyzed in elasto-plastic range is shown in Fig.2 as "H" shaped frame which includes upper columns adjacent to fire exposed members. This substructure is analyzed, separated from the whole structure and acted on by restraint forces. Adjacent substructure occupies 6 stories, containing upper and lower 2 stories of the local substructure.
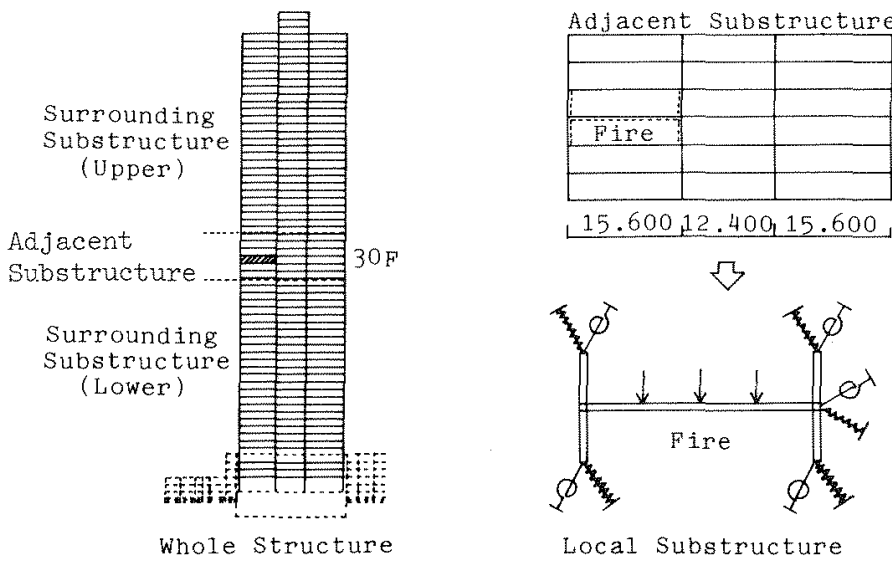

Local Substructure

Fig.2 The Outline and Division of Real Structure (Example A ) 
Thermal stress analysis of the local substructure is carried out by using "a non linear direct stiffness formulation coupled with a time step integration" /13/. The assumptions of the analysis are as follows.

(1) Time dependent temperature variation is assumed step-wise and temperature distribution of the member remains constant within a fiven time step.

(2) Beams and columns which constitute the local substructure are divided longitudinally into segments. In the example referred,beams are divided into 12 segments and columns into 7 segments.

(3) Segments are further divided into subslices within the cross section; in the example, flange into 2 subslices and web into 6 subslices.

(4) Strain distribution remains plane according to Bernoulli's hypothesis.

(5) Total strain $\varepsilon$ in segment consists of instantaneous stress-strain $\varepsilon^{5}$ and thermal expansion strain $\varepsilon^{T}$. Creep $\operatorname{strain} \varepsilon^{c}$ is neglected for simplification.

$$
\varepsilon=\varepsilon^{\mathrm{s}}+\varepsilon^{\top}
$$

(6) Instantaneous stress-strain is defined as follows $/ 16 /$.

$$
\varepsilon^{\mathrm{s}}=\varepsilon^{e}+\varepsilon^{\mathrm{p}}=\sigma{ }_{0} \mathbf{E}_{\mathbf{T}}+\left.\mathbf{|} \sigma \sigma_{\mathrm{k}}\right|^{\mathrm{k}} \operatorname{sgn}(\sigma)
$$

where $\varepsilon^{\mathrm{e}}=$ elastic strain, $\varepsilon^{\mathrm{P}}=$ plastic strain, $\sigma=$ stress,

${ }_{\mathbf{0}} \mathbf{E}_{\mathbf{r}}=$ initial modulus of elasticity and $\sigma_{\mathbf{k}}, \mathbf{k}$ are quantities which determine plastic strain from stress-strain curve.

(7) Thermal strain is defined as follows/12,13/.

$$
\varepsilon=\alpha T=(10.8+0.00675 T) T \times 10^{-6}
$$

48 buildings were analyzed whose structural data were available and which had been permitted to be constructed by 1980 . These are listed in Table 1. The buildings are grouped into 7 types according to location and size of fire compartment in a floor. The compartment fire is assumed to be Standard Fire.

The computational analysis was carried out for the building structure shown in Fig. 2 (type A,building No.43 in Table 1), supposing compartment fire on 30 th floor. Results are given in Fig. $3 \% 6$. As show in Fig. 3 , development of the bending moment is remarkable at the top and bottom of the columns due to the thermal elongation of the beam exposed to fire. $\mathrm{Fig} .4$ shows that the bending moments increase to a maximum at about $400^{\circ} \mathrm{C}$, and then decrease following to reduction of load bearing capacity. As shown in Fig.5, horizontal displacement at top of the outer column is larger than that of the inner column. This difference occurs because the stiffness on the outer column side is smaller than that of inner column side.

Baila. No.43-30F[Moment of Beams(tm) Temp.400 " C

Buila. No.43-30F[Moment of Columis $(\operatorname{tm})]$ Temp.400 "C
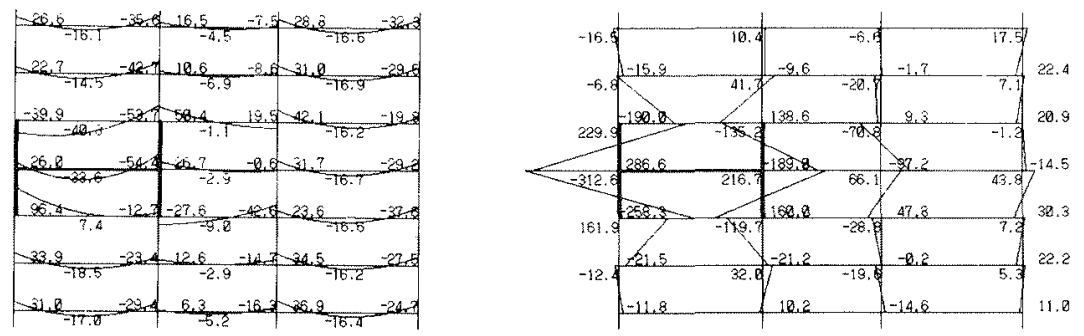

Local Substructure

Adjacent Substructure

Fig. 3 Moment Distribution in the Local and Adjacent Substructure 


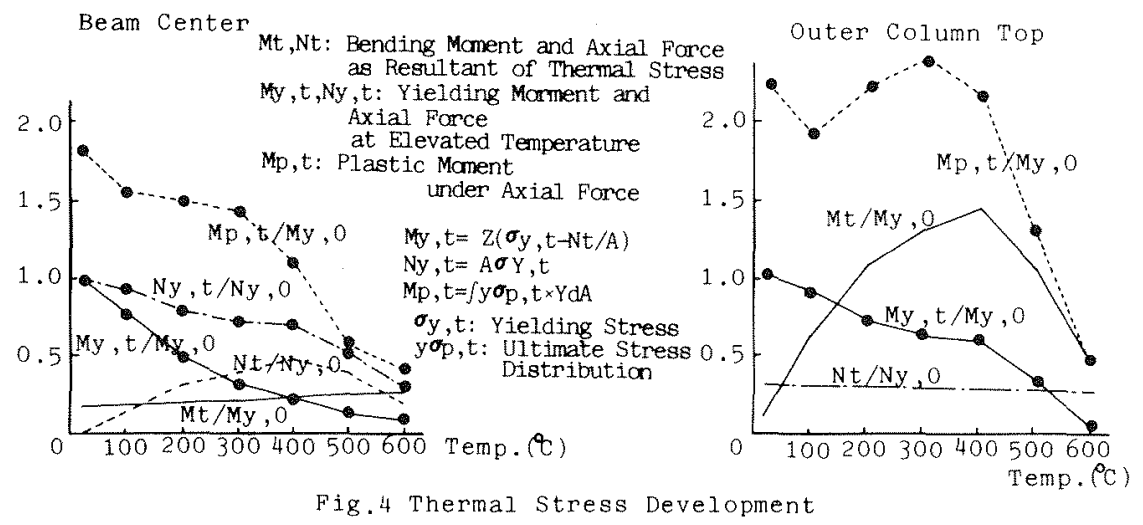

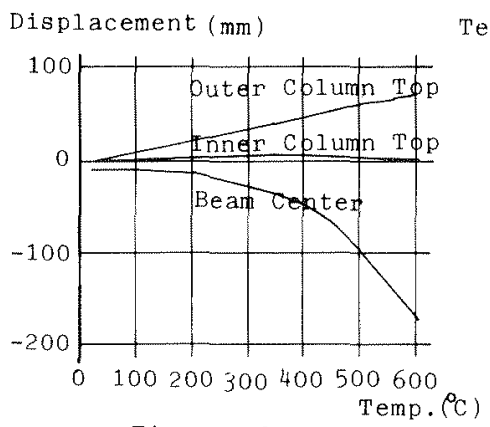

Fig. 5 Deformation

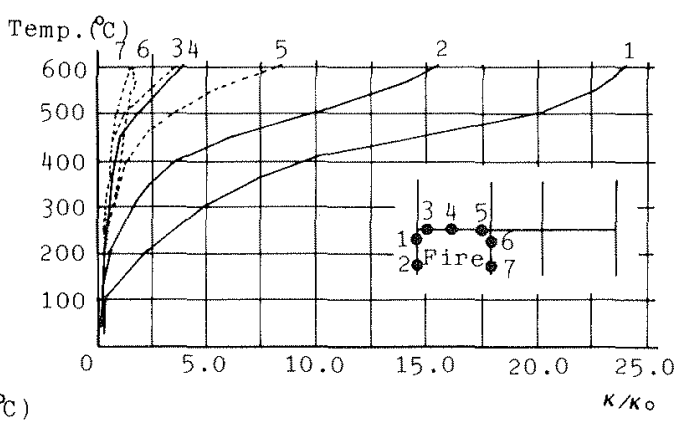

Fig. 6 Curvature

The deflection of the beam begins its rapid increase beyond $300^{\circ} \mathrm{C}$. $\mathrm{Fig} .6$ shows the curvatures at indicated points of the fire exposed beam and columns. At $600^{\circ} \mathrm{C}$, the curvatures at the top and bottom of the outer column amount to $15 \sim 20$ times of the yielding curvature. At the center and both ends of the beam, the corresponding value is $4 \sim 9$ times of the yielding curvature.

\section{SUMMARY OF RESUTTS}

The summary of the numerical results from the analysis of 48 building structures are shown in Table 2 .

\section{Thermal Stress}

Significant thermal stresses occur in the local substructure constituting the compartment directly exposed to fire. Especially, the bending moments increases to high values at the top of the outer column (inner ones in type B) which are directly affected by the thermal. elongation of beam, exposed to fire. The bending moments reaches their maximum value around $400^{\circ} \mathrm{C}$ and then decreases following the reduction of 
load bearing capacity. In general, the axial force practically remain constant in the outer column but increase a little in the innex column. Due to restraint on both sides, the axial force in the fire exposed beam increases remarkably. It reaches about $50 \%$ of yield axial force around $400^{\circ} \mathrm{C}$ and then decreases to nearly zero at $600^{\circ} \mathrm{C}$. On the other hand the variation of the bending morment in this beam is relatively small.

Table 2 shows yield temperature at which thermal stress reaches the yield point stress at the top of outer colum and center of beam exposed to fire. The yield temperature at the top of the outer column is $115^{\circ} \mathrm{C}$ as minimum, $444^{\circ} \mathrm{C}$ as maximum and $189^{\circ} \mathrm{C}$ as average. The tendency is recognized in the yield temperature of the column where it becomes lower as the beam connected to the colum becomes longer. Yield temperature in the beam is higher than that of the column, namely, $188^{\circ} \mathrm{C}$ as minimum, $568^{\circ} \mathrm{C}$ as maximum and $388^{\circ} \mathrm{C}$ as average.

Curvature

In some of the analyzed building structures, plastic rotations are noticeable at the top and bottom of the outer columns and at the center and the ends of the beam. Some of the maximum curvatures at these sections amounts to 50 times the $y i e l d$ curvature at room temperature. The temperatures at which the curvature exceeds 10 times the yield curvature at room temperature are shown in Table 2 as "Plastic hinge temperature". According to this definition, plastic hinges occur at $428^{\circ} \mathrm{C}$ and $501^{\circ} \mathrm{C}$ in average on the top and bottom of outer colum, respectively. There are 15 building strucrures in which plastic hinge occurred on beams. In 7 buildings, namely, No.12,17,19,23,28,29,49, three plastic hinges occur at the center and the ends of the beam, $i$,e, a collapse mechanism is developed.

Deflection

There are several test standard criteria for a definition of structural failure or instability of columns and beams, exposed to fire. In this paper, deflection criteria used are $I^{2} / 800 \mathrm{H}$ for beams and $\mathrm{h} / 30$ for columis. $\mathrm{L}$, II and $\mathrm{h}$ are beam length, beam depth and colum height, respectively. Horizontal deflection of column top and vertical deflection of beam center at $600^{\circ} \mathrm{C}$ divided by these criteria are shown in Table 2 as "Maximum deflection". Maximum deflection ratio(=calculated deflection / deflection according to criterion) for colum is found for building structure type $\mathrm{C}, \mathrm{No} .39$, amounting to $65 \%$. There is a tendency that longer span beams have larger deflection ratio. Building structures in which beam deflection ratio exceeds $80 \%$ are No.12,23,28 of type $A$ and No.17,19,29 of type $B$. Beam collapse mechanisms are then developed for all these buildings.

\section{CONCLUSTON}

(1) It is sufficiently safe when a high rise steel structure is designed according to existing Japanese fire resistance critexia (below av. $350^{\circ} \mathrm{C}$ and $\max .450^{\circ} \mathrm{C}$ ) because necessary load bearing capacity is maintained though yield zones and plastic hinges may appear before the criteria are reached.

(2) Some of long span beams will get collapse mechanisms if they are designed according to allowable temperature $600^{\circ} \mathrm{C}$ which is permitted in some countries.

(3) It is verified that the suggested calculation method based on division of structure into three types of substructures is suitable for high rise building structures exposed to compartment fire. 
Table 1. List of High Rise Buildings Investigated

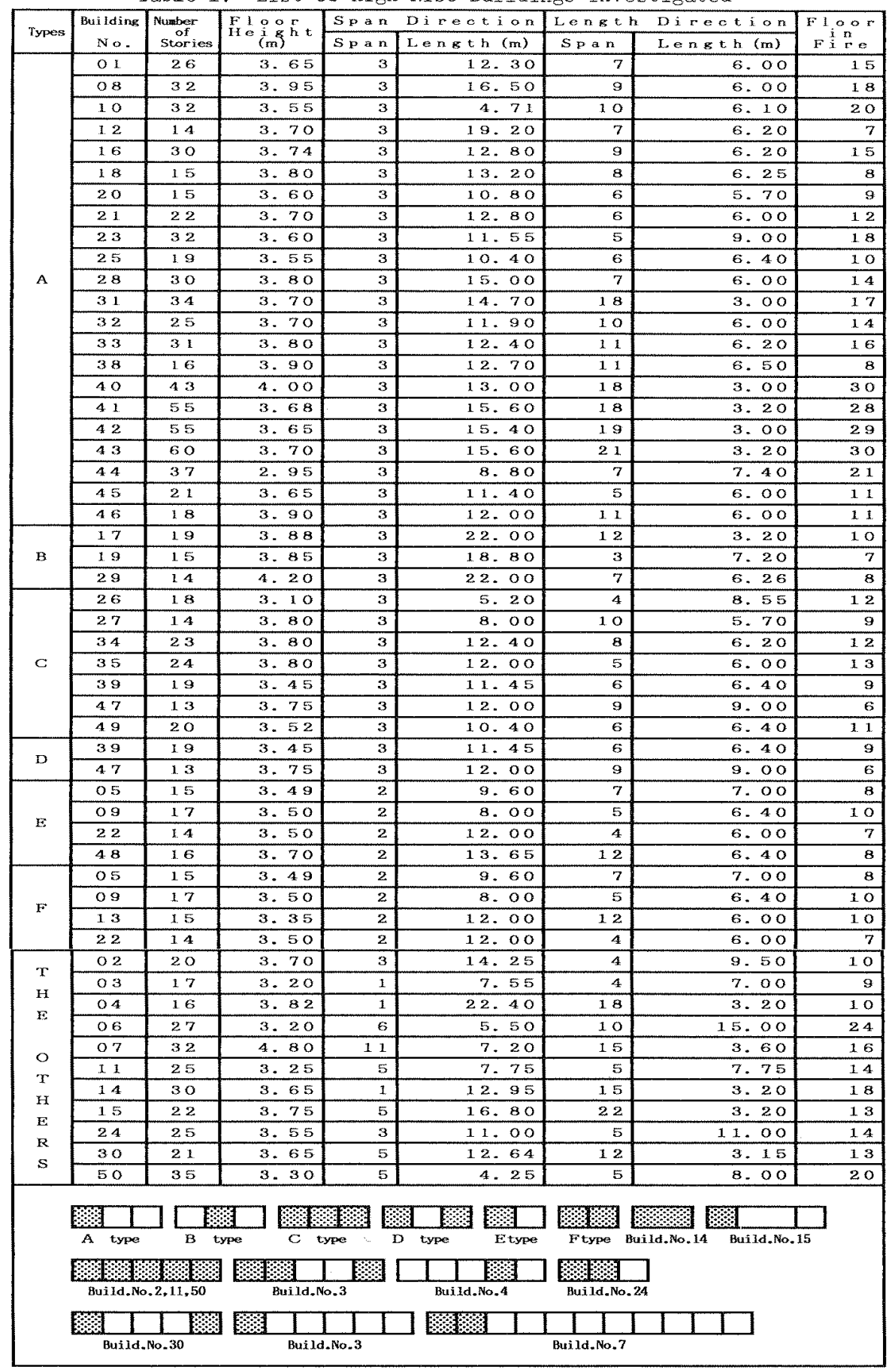


Table 2. The Results of Numerical Analysis

\begin{tabular}{|c|c|c|c|c|c|c|c|c|c|c|c|c|}
\hline \multirow{3}{*}{ Typess } & \multirow{3}{*}{$\begin{array}{l}\text { Buileting } \\
\text { No. }\end{array}$} & \multicolumn{2}{|c|}{ Service Laad Rate } & \multirow{2}{*}{\multicolumn{2}{|c|}{$\begin{array}{l}\text { Yieldine } \\
\text { Temp. (x) }\end{array}$}} & \multicolumn{5}{|c|}{ Plastic Hinge Temoserature $(\mathrm{CC})$} & \multirow{2}{*}{\multicolumn{2}{|c|}{$\begin{array}{c}\text { Maxi mulm } \\
\text { Deflection }(600 \%)\end{array}$}} \\
\hline & & Axial N. & Bend. $M$. & & & \multirow{2}{*}{$\begin{array}{l}\text { Outerer } \\
\text { Colum } \\
\text { Toxp }\end{array}$} & \multirow{2}{*}{ 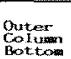 } & \multirow{2}{*}{ Berext } & \multirow{2}{*}{ cerst. } & \multirow{2}{*}{$\begin{array}{l}\text { Beam } \\
\text { Ritht }\end{array}$} & & \\
\hline & & \begin{tabular}{|l|} 
Inner \\
Collumis
\end{tabular} & $\begin{array}{l}\text { Beasu } \\
\text { Censtex }\end{array}$ & $\begin{array}{l}\text { Quterer } \\
\text { Colutum }\end{array}$ & $\begin{array}{l}\text { Boam } \\
\text { Crentex }\end{array}$ & & & & & & Bean & $\begin{array}{l}\text { Outer } \\
\text { Colarums }\end{array}$ \\
\hline \multirow{22}{*}{ A } & 01 & 0.14 & 0.08 & 174 & 512 & 385 & 460 & $=$ & $=$ & $=$ & 0.276 & 0.496 \\
\hline & 08 & 0.28 & 0.26 & 183 & 417 & 430 & $=$ & $=$ & - & $=$ & 0.535 & 0.320 \\
\hline & 10 & 0.12 & 0.02 & 347 & 479 & & - & $=$ & -..- & - & 0.128 & 0.094 \\
\hline & 12 & 0.18 & 0.34 & 115 & 272 & 375 & 490 & 500 & 520 & 450 & $x .051$ & 0.555 \\
\hline & 16 & 0.23 & 0.14 & 171 & 457 & 420 & $5+5$ & $=$ & - & - & 0.422 & 0.3755 \\
\hline & 18 & 0.09 & 0.10 & 186 & 500 & 405 & 480 & $=$ & $=$ & - & 0.297 & $0.46 \mathrm{~B}$ \\
\hline & 20 & 0.14 & 0.10 & 189 & 586 & 440 & 500 & $=$ & - & - & 0.180 & 0.521 \\
\hline & 21 & 0.16 & 0.16 & 194 & 477 & 440 & 515 & - & $=$ & 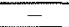 & 0.338 & 0.458 \\
\hline & 23 & 0.24 & 0.30 & 183 & 300 & $=$ & $=$ & 540 & 500 & 52.5 & 0.873 & 0.158 \\
\hline & 25 & 0.12 & 0.04 & 273 & 426 & $=$ & - & $=$ & - & - & 0.106 & 0.401 \\
\hline & 28 & 0.47 & 0.42 & 142 & 258 & 455 & $=$ & 515 & 545 & 490 & 1.254 & 0.442 \\
\hline & 31 & 0.30 & 0.23 & 154 & 300 & 445 & 590 & 600 & $=$ & 550 & 0.555 & 0.434 \\
\hline & 32 & 0.14 & 0.10 & 200 & 443 & 460 & $=$ & $=$ & - & $=$ & 0.382 & 0.332 \\
\hline & 33 & 0.25 & 0.20 & 143 & 414 & 405 & 475 & $\ldots$ & - & $-m$ & 0.321 & 0.591 \\
\hline & $3 a$ & 0.14 & 0.18 & $19 x$ & 426 & 445 & 575 & $=$ & 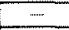 & 590 & 0.412 & \begin{tabular}{|c|}
0.404 \\
\end{tabular} \\
\hline & 40 & 0.14 & 0.12 & 116 & 500 & 475 & & - & $=$ & $=$ & 0.304 & 0.159 \\
\hline & 41 & 0.38 & 0.27 & 140 & 340 & 120 & 510 & - & - & 580 & 0.493 & 0.635 \\
\hline & 42 & 0.30 & 0.17 & 134 & 454 & 400 & 180 & $=$ & $=$ & $=$ & 0.420 & 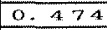 \\
\hline & 43 & 0.28 & 0.19 & 146 & 400 & 405 & 500 & - & - & - & 0.440 & 0.585 \\
\hline & 44 & 0.15 & 0.23 & 263 & 386 & - & & 455 & $=$ & 455 & 0.696 & 0.128 \\
\hline & 45 & 0.10 & 0.07 & 192 & 500 & $A 15$ & 500 & - & - & - & 0.220 & 0.4655 \\
\hline & 46 & 0.16 & 0.14 & 184 & 4033 & 430 & 490 & $=$ & $=$ & - & 0.139 & 0.556 \\
\hline \multirow{3}{*}{ I3 } & 17 & 0.11 & 0.42 & 200 & 168 & $=$ & - & 400 & $\angle B O$ & 400 & 1.206 & 0.109 \\
\hline & 19 & 0.11 & 0.24 & 197 & 317 & $=$ & $=$ & 550 & 560 & 550 & 0.821 & 0.122 \\
\hline & 29 & 0.12 & 0.23 & 217 & 240 & $=$ & $=$ & 485 & 560 & 485 & 1. 023 & 0.075 \\
\hline \multirow{7}{*}{$c$} & $2 \epsilon$ & $8: 87$ & $8: 8$ 涪 & 228 & \begin{tabular}{|l|l|}
116 \\
565 \\
425 \\
\end{tabular} & 488 & $\underline{-}$ & $\Xi$ & $\overline{=}$ & $=$ & $\begin{array}{l}\text { 8: } 218 \\
0: 3 \\
0\end{array}$ & 8: 련 \\
\hline & 27 & $8: 86$ & $\begin{array}{l}8: 85 \\
0: 81 \\
0\end{array}$ & 197 & 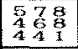 & 458 & 548 & $=$ & $=$ & $\cdots$ & 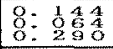 & $8: 478$ \\
\hline & 34 & $8: \frac{17}{17}$ & $\begin{array}{l}8: 15 \\
8: 0 \\
0\end{array}$ & $\begin{array}{l}1653 \\
163\end{array}$ & $\begin{array}{l}400 \\
400 \\
400\end{array}$ & 485 & $=$ & $\begin{array}{l}590 \\
575\end{array}$ & $=$ & $\begin{array}{l}575 \\
590\end{array}$ & 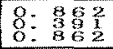 & $8: 328$ \\
\hline & 35 & $8: 13$ & 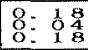 & $\frac{164}{16}$ & \begin{tabular}{|l|}
365 \\
365 \\
365 \\
365
\end{tabular} & 485 & 558 & $=$ & $=$ & $=$ & $\begin{array}{l}8: 539 \\
8: 583 \\
0: 539\end{array}$ & 8: 莐17 \\
\hline & 39 & $8: 15$ & $8: \begin{array}{l}15 \\
0: 07 \\
15\end{array}$ & 168 & $\begin{array}{ll}430 \\
430 \\
43\end{array}$ & 338 & 425 & $=$ & 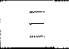 & $\bar{E}$ & 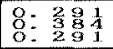 & 8: 65 \\
\hline & 47 & $8: 81$ & $\begin{array}{l}8: 88 \\
8: 82\end{array}$ & $\begin{array}{l}157 \\
157\end{array}$ & 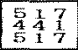 & 338 & 138 & 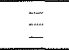 & $=$ & $=$ & $\begin{array}{l}8: 264 \\
8: 213 \\
0\end{array}$ & $8: 538$ \\
\hline & 49 & 8 & $\begin{array}{l}8: 27 \\
0: \frac{2}{2}\end{array}$ & $\begin{array}{l}118 \\
118\end{array}$ & $\begin{array}{l}472 \\
375 \\
472\end{array}$ & 388 & $58 \%$ & $\begin{array}{l}487 \\
43 \\
4 \\
4\end{array}$ & 520 & $\begin{array}{ll}4 \\
4 \\
43 \\
83\end{array}$ & $\begin{array}{l}8: 588 \\
8: 584 \\
588\end{array}$ & $8: 481$ \\
\hline \multirow{2}{*}{ D } & 39 & $8: \frac{15}{15}$ & 8: 85 & 191 & 453 & 3998 & 475 & $\bar{E}$ & $=$ & $=$ & $8: 276$ & $8: 557$ \\
\hline & 47 & $8: 84$ & $8: 8 \frac{8}{2}$ & 174 & 538 & 378 & 458 & - & 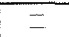 & $=$ & $8: 2 \frac{66}{6} 6$ & $8: 583$ \\
\hline & 05 & 0.12 & 0.10 & 246 & 457 & 490 & -- & $=$ & - & - & 0.442 & 0.175 \\
\hline$E$ & 08 & 0.09 & $0.0 E$ & 254 & 560 & 460 & 550 & - & - & - & 0.192 & 0.334 \\
\hline & 22 & 0.12 & 0.16 & 180 & 449 & 405 & 465 & $=$ & $-\cdots$ & - & 0.480 & 0.347 \\
\hline & 48 & 0.14 & 0.12 & 194 & 440 & 430 & - & $=$ & - & - & 0.505 & 0.280 \\
\hline & 05 & 0.12 & o: 18 & $\begin{array}{l}1639 \\
1698\end{array}$ & $\begin{array}{lll}4 & 2 \\
4 & 1 \\
\end{array}$ & 458 & $\div$ & $=$ & $=$ & $\equiv$ & $8: 476$ & $8: \frac{24}{21}$ \\
\hline & 09 & 0.09 & $8: 86$ & $\begin{array}{l}194 \\
194\end{array}$ & 558 & ${ }_{448}^{448}$ & 528 & $=$ & $=$ & $\Xi$ & $8: 219$ & $8: 36 \frac{1}{36}$ \\
\hline$F^{\prime}$ & 13 & 0.14 & $8: \frac{1}{13}$ & $\frac{177}{17}$ & 458 & 588 & 600 & $=$ & $=$ & $=$ & $8: 443$ & $8: 373$ \\
\hline & 22 & 0.12 & $8: 166$ & $\frac{179}{157}$ & $\begin{array}{|lll|}5 & 4 & 4 \\
4 & 1 & 6 \\
\end{array}$ & 399 & 488 & $=$ & $\bar{E}$ & $5 \overline{9} 5$ & $8: \frac{21}{5} \frac{1}{9}$ & $8: 37 \frac{7}{3}$ \\
\hline & 2 & 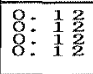 & $\begin{array}{l}8: 17 \\
8: 017 \\
8: 017 \\
8: 17\end{array}$ & 188 & 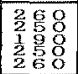 & 468 & $=$ & $\bar{z}$ & $\begin{array}{l}\bar{E} \\
\bar{E}\end{array}$ & $\begin{array}{l}\bar{E} \\
\bar{z}\end{array}$ & $\begin{array}{l}8: 493 \\
8: 294 \\
8: 290 \\
804\end{array}$ & $8: 2 \frac{273}{3}$ \\
\hline & 03 & $\begin{array}{l}8: 86 \\
8: 86 \\
15\end{array}$ & $\begin{array}{l}8: 81 \\
0: 8 \frac{1}{2}\end{array}$ & $\frac{44}{32} 6$ & $\begin{array}{l}350 \\
258 \\
25\end{array}$ & $\bar{z}$ & $\bar{z}$ & $\bar{Z}$ & $\bar{z}$ & $=$ & $8: 837$ & 0.150 \\
\hline & 04 & 0.10 & 0.20 & 170 & 410 & 420 & 175 & 580 & $=$ & 580 & 0.581 & 0.353 \\
\hline 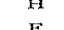 & 06 & 0.02 & 0.02 & 380 & - & 600 & $=$ & $=$ & $=$ & $=$ & 0.313 & 0.175 \\
\hline & 07 & 0.08 & 0.12 & 230 & $5 \overline{9} 0$ & 520 & 580 & 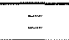 & $=$ & $=$ & $8: 1 \frac{1}{3} \frac{6}{2}$ & 0.469 \\
\hline $\begin{array}{l}O \\
T \\
H\end{array}$ & 11 & 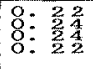 & $\begin{array}{l}8: 89 \\
8: 89 \\
8: 89\end{array}$ & $\begin{array}{l}152 \\
152\end{array}$ & 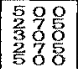 & 418 & $\bar{E}$ & $\begin{array}{l}E \\
E\end{array}$ & $\equiv$ & $\equiv$ & $\begin{array}{l}8: 281 \\
8: 681 \\
8: 681 \\
6281\end{array}$ & $8: 4 \frac{26}{2}$ \\
\hline$E$ & 14 & 0.11 & 0.17 & 304 & 280 & - & - & 545 & $=$ & 545 & 0.732 & 0.072 \\
\hline $\mathbf{R}$ & 15 & 0.12 & 0.17 & 207 & 530 & 455 & 50 & $=$ & $=$ & - & $0.33 x$ & 0.251 \\
\hline s & 24 & $8: \frac{1}{18}$ & $8: 88$ & 140 & $\begin{array}{l}498 \\
418\end{array}$ & 315 & 420 & 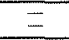 & $\bar{E}$ & $\bar{E}$ & $8: \frac{289}{4}$ & 0.530 \\
\hline & 30 & $8: \frac{14}{14}$ & $8: 26$ & 178 & 388 & 385 & 465 & $\equiv$ & $\equiv$ & $\equiv$ & $8: 32 \frac{1}{1}$ & $8: 544$ \\
\hline & 50 & 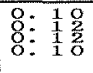 & $\begin{array}{l}8: 03 \\
8: 83 \\
8: 83 \\
8: 83\end{array}$ & $\begin{array}{l}185 \\
185\end{array}$ & \begin{tabular}{|l|}
448 \\
38 \\
38 \\
398
\end{tabular} & 688 & $\equiv$ & $\begin{array}{l}\equiv \\
\equiv\end{array}$ & $\equiv$ & $\begin{array}{l}\bar{E} \\
\underline{\underline{E}}\end{array}$ & $\begin{array}{l}8: 259 \\
8: 259 \\
8: 259\end{array}$ & 0.196 \\
\hline
\end{tabular}


This calculation for high rise building structures was accomplished on the help of undergraduate and graduate students of Chiba University. The author: thank for their helpfulness.

\section{REFRRENCES}

11 H. Saito, Y. Shimizu, "Bending Experiments of steel beams at Elevated Temperature" Trans. of A. I.J. No. 89, September 1963. (in Japanese) 2/ K. Takano, "A study on Fire Resistance of Steel structural Members" pp. 84-109, Dissertation, 1983. (in Japanese)

/3r Saito, "Behavior of End Restrained steel Members under Fire" Bulletin of the Fire preventi on Society of Japan, Vol. 15 No. 1, Jan., 1966. (in Japanese)

/4/ Culver, C. Aggarwal, V., and Ossenbruggen, P., "Steel Column Failure under Thermal Gradients" "Journal of the Structural Division, ASCE, Vol. 99. No. ST4, April, 1973.

/5/ Culver, C. Aggarwal, V., and Ossenbruggen, P. "Buckling of Steel Columns at Elevated Temperatures" ", Journal of the Structural Division, ASCE, Vol. 99 , No.ST4, April. 1973

16/ Cheng, W.C. and Mak.C.K. "Computer Analysis of Steel Frame in Fire." Journal of Structural Division, ASCE, Vol, 101, No. ST4, April, 1975.

7/ H. Saito, "Thermal stress on steel Structural Frames", Trans., A. I.J., 1969. (in Japanese)

18/ K. Migita, T. Okabe, "A Study on Thermal-stress Analysis of the Steel Frames, exposed to Fire", Trans. A.I.J.,1882. (in Japanese)

19/ H. Furumura, Y. Shinohara, "Inelastic Behavior of Protected Steel Beams and Frames in Fire". Trans. A. I.J., Vol.300, Feb., 1981.

$110 /$ H. Saito, H. Uesugi, A.Kodaira, O.Konno, Thermal Stress of steel Structures of "Tall Building in Fire", Fire science and Technology Vol. 1.3 No. 2, 1983 .

11, Cheat, E.K." "Stress Analysis of steel Frame Structures with Nonrigid Comections subjected to Thermal Gradient., Trans. of A. I. J., No. 346 , December, 1984 .

12, Tasnim Uddin, C.G. Culver, " Effects of Elevated Temperature on Structural Members", Journal of the structural Division, ASCE, Vol. 101, No. ST7, July 1975

13/ Becker, J., Bresler, B., "FIRES-RC-w- A Computer Program for the fire Response" of Structure -m-keinforced Concrete Frames", Report No. UCB FRG74-3, University of California Berkley, July, 1974.

114 H. Uesugi, H. Koike, M. Yamaguahi, A. Kodaira, H. Saito, "Behavior of Steel structures of Tall Bujldings in Fire", Bulletin of The Fire Prevention Society of Japan, May, 1986. (in Japanese)

15, Y. Harada, K. Migita, Y. Makino, "Calculation of Stress and Deformation of High Rise Frames in Fire", Trans. A. I.J., Oct., 1966. (in Japanese)

16, J.Hult, "Creep in Engineering Structures", published from Blasdell Publ ishing Company, A Division of Ginn and Company, 1966

r17, Witteveen,J., Twilt,L. and Bi.jlaard, F.S.K. :The Stability of Braced and Unbraced Frames at Elevated Temperatures, Symposium on stability of steel Structures, Liege, April 1977

/18/ Beyer, R. Der Feuerwiderstand von Tragwerken aus Baustahl. Berechnung mit Hilfe des Traglastverfahrens, Stahlbau, Vol. 46, No. 12, 1977.

119, Beyer, R. and Hartmann, B. : Eine Untersuchung des Lastfalles Brand bei Stahl rahmen, Kol loquium fü Finite Elemente in der Baupraxis, Hannover, Apri I 1978 .

120/ Iding, R.H. and Bresler, B. : Effect of Fire Exposure on Steel Frame Buildings (Computer Model FASBUS II ), Final Report WJE 78124 Wiss, Janney, Elstner and Associates, Inc., September 1981 .

21/ Petersson, A. : Finite Element Ánalysis of Structures at High Temperatures, with special Application to plane steel Beems and Frames, Lund Institute of Technology, Division of Structural Mechanics, Report TVSN-1001, Lund, 1984

22/ CEC Reearch 7210-SA/502-REFAO/CAFIR: Computer Assisted Analysis of the Fire Resistance of Steel and Composite Steel-Concrete structures (Computer Program CEF ICOSS), Technical Report RT $1-6,1982 / 85$.

123/ Forsen, N.E. :STEELFIRE-Finite Element program for NonLinear Analysis of Steel Frames Exposed to Fire, Users manual, Multiconsult A/S, Oslo, 1983. 